\title{
Potencial produtivo e resistência à virose em linhagens e cultivares de amendoim na região de Tupã, São Paulo
}

Engenheiro Agrônomo, Tupã - SP, e-mail: rodolfopiresribeiro@gmail.com.

Rodolfo Pires Ribeiro (D) Rafael Luiz Rocha Vanderley
Engenheiro Agrônomo, Tupã - SP, e-mail: raphael_Irv@hotmail.com.

Engenheiro Agrônomo, Tupã - SP, e-mail: marcel.agro@hotmail.com.

\section{João Francisco dos Santos iD}

Pesquisador Visitante do IAC, Campinas - SP, e-mail: joaofsantos@iac.sp.gov.br.

\section{Marcos Doniseti Michelotto (iD)}

Pesquisador Científico da APTA, Pindorama - SP, e-mail: michelotto@apta.sp.gov.br.

\section{Andrea Rocha Almeida de Moraes (iD}

Pesquisadora Científica do IAC, Campinas - SP, e-mail: andrea@iac.sp.gov.br.

\section{Ignácio José de Godoy ${ }^{\text {iD }}$}

Pesquisador Científico do IAC, Campinas - SP, e-mail: ijgodoy@iac.sp.gov.br.

\section{RESUMO}

Novas linhagens destacadas do programa de melhoramento de amendoim devem passar por cultivos experimentais em parcelas amplas junto a campos de produtores. Nove linhagens e cultivares de amendoim foram avaliados no município de Tupã, SP, na safra 2019/2020, em um experimento em campo, semeados em três épocas durante o ciclo de cultivo, em parcelões de seis linhas de dez metros. $O$ manejo de cultivo foi o utilizado regularmente para a cultura de amendoim. Nas parcelas semeadas na segunda e terceira épocas, ocorreu infestação por vírus, caracterizado como o tospovirus GRSV, tendo assim, cada parcela sido avaliada quanto ao número de plantas com sintomas da virose. Os dados obtidos mostraram as maiores produtividades na primeira época de semeadura, decrescendo na segunda e na terceira época. Entre os genótipos avaliados, a linhagem 11.20 obteve alto potencial produtivo, especialmente na primeira época de semeadura. A linhagem 10.677 apresentou maior estabilidade produtiva, a maior produtividade na média das três épocas de plantio, além do menor número de plantas infestadas com vírus, indicando potencial de resistência à doença.

Palavras-chave: Arachis hypogaea L.; Melhoramento genético de amendoim; Virose.

\section{Productive potential and resistance to virosis in lines and cultivars of peanuts in the region of Tupa, Sao Paulo}

\section{ABSTRACT}

New peanut lines selected from the breeding programs hould also be planted in large plots next to grower's fields. Nine peanut breeding lines and cultivars were evaluated in Tupã, SP, during the 2019/2020 growing season in an experiment comprising three planting dates in large plots of six rows of ten meters. Cultivation management was as the indicated for the peanut crop in São Paulo. Plots of the second and third planting dates were infested by vírus, with symptoms characteristic of GRSV (Groundnut Ringspot Virus). Each of these plots was then evaluated for 
the number of plants with virus symptoms. Yield data showed the highest values in the first planting, and a decrease in the second and third planting date. Among all genotypes tested, line 11.20 showed the highest yield especially at the first planting date. Line 10.677 showed a good yield stability and the highest average yield over the three planting dates. This line also presented the lowest number of vírus infested plants, indicating a potential for vírus resistance.

Keywords: Arachis hypogaea L.; Peanut breeding; virus.

\title{
Potencial productivo y resistencia a la virosis en líneas y cultivares de mani en la región de Tupa, San Pablo
}

\section{RESUMEN}

\begin{abstract}
Nuevas líneas de maní destacadas del programa de mejoramiento deben pasar por cultivos experimentales en parcelas largas junto a campos comerciales. Nueve líneas y cultivares de maní fueron evaluados em el período 2019/20 mediante um experimento instalado em tres épocas de siembra em parcelas de seis surcos de diez metros de longitude. El manejo del cultivo fue igual a um campo convencional de maní. En las parcelas instaladas la segunda y terceira época ocurrió uma infestación por tospovirus GRSV, por esse motivo fueran evaluadas el número de plantas com sintomas. Los datos mostraron los mayores rendimentos en la primera época de siembra, disminuyendo em la segunda y terceira épocas. Entre los genótipos evaluados, la línea 11.20 evidenció un alto potencial productivo, especialmente en la primera época. La línea 10.677 presentó mayor estabilidade productiva y el máximo rendimento promedio de las tres épocas. Esta línea tuvo también el menor número de plantas infestadas por vírus, presentando potencial de resistência a la enfermedad.
\end{abstract}

Palabras clave: Arachis hypogaea L.; Mejoramiento de maní, Vírus.

\section{Introdução}

O programa de melhoramento genético de amendoim do Instituto Agronômico - IAC, após obter e identificar linhagens elite no programa realiza testes ou experimentos de validação do material, em parcelas maiores do que se utiliza em ensaios regulares de linhagens. Estes geralmente incluem muitas linhagens e, para que se tornem exequíveis, utilizam parcelas pequenas.

Os testes em parcelas maiores permitem melhor visualização das qualidades do material, especialmente quando realizados junto aos campos de produção, nas condições de cultivo da região, e conduzidos pelos próprios produtores.

Entre as características a serem avaliadas nesta etapa pósmelhoramento, o potencial produtivo é sempre uma característica a ser buscada, mas a estabilidade produtiva também é importante na escolha dos 
melhores materiais, pois reflete a sua capacidade de manter médias desejáveis de produtividade em diversos ambientes (SANTOS et al., 2018).

Em um teste em parcelões realizado na safra 2019/2020, um conjunto de linhagens e cultivares do IAC foi avaliado, plantando-se cada material no mesmo local em 3 épocas durante a estação de cultivo, com a finalidade de observar o comportamento das linhagens e cultivares criandose uma diversidade de ambientes e permitindo a realização de análise estatística dos dados. Assim, com o plantio no mesmo local, os fatores relacionados com o solo, que podem interferir nas comparações de desempenho entre os materiais, são minimizados.

No período coincidente com o máximo desenvolvimento vegetativo do plantio de $2^{a}$ época, ocorreu uma infestação de virose, que atingiu o ensaio e as lavouras plantadas em seu entorno. Em função disso, optou-se por realizar uma avaliação do material quanto à possibilidade de se detectar genótipos com possível resistência ou tolerância à doença. Em pesquisas anteriores, observou-se que essa virose é causada pelo tospovírus GRSV (Groundnut ringspot virus), transmitida por tripes da espécie Frankliniella schultzei (CAMELO-GARCIA et al., 2014; CULBREATH et al., 2003).

Em áreas com incidência da doença, perdas na produção de vagens foram estimadas em $38 \%$ e os prejuízos são intensificados quando há redução no estande de plantas, chegando a $64 \%$ a redução na produção (MICHELOTTO et al., 2019).

Desse modo, este trabalho teve por objetivo relatar os resultados da avaliação de genótipos quanto à produtividade, estabilidade produtiva e reações à virose causada pelo tospovírus GRSV (Groundnut ringspot virus).

\section{Material e métodos}

O experimento foi plantado no município de Tupã (latitude $22^{\circ} 0,0^{\prime}$ $37,85^{\prime \prime}$ S e longitude $50^{\circ} 32^{\prime} 40,40^{\prime \prime}$ W), estado de São Paulo, em solo podzolizado com baixo teor de argila. Após a análise do solo, realizou-se a aplicação de $2.000 \mathrm{Kg} \mathrm{ha}^{-1}$ de calcário dolomítico na área e antes da 
semeadura o solo foi adubado com $300 \mathrm{Kg} \mathrm{ha}^{-1}$ da fórmula (NPK) 2-27-10. Todos os tratos culturais e fitossanitários foram feitos conforme recomendações técnicas para a cultura do amendoim (GODOY et al., 2005).

Os genótipos estudados foram: cultivares IAC OL3, IAC Sempre Verde, IAC OL5, e linhagens 11.20, 11.27, 11.29, 10.677, 10.719 e 599.

Cada parcela foi constituída de 6 linhas de 10 metros de comprimento e 0,9 metros de espaçamento entre linhas. $O$ plantio da $1^{\text {a }}$ época foi realizado em 25/10/2019, o da $2^{a}$ época em 13/11/2019 e, da $3^{a}$ época, em 15/12/2019. Nas três épocas, as sementes apresentaram boa emergência e as plantas um bom desenvolvimento. Os dados de precipitação pluviométrica no período do experimento são apresentados na Figura 1.

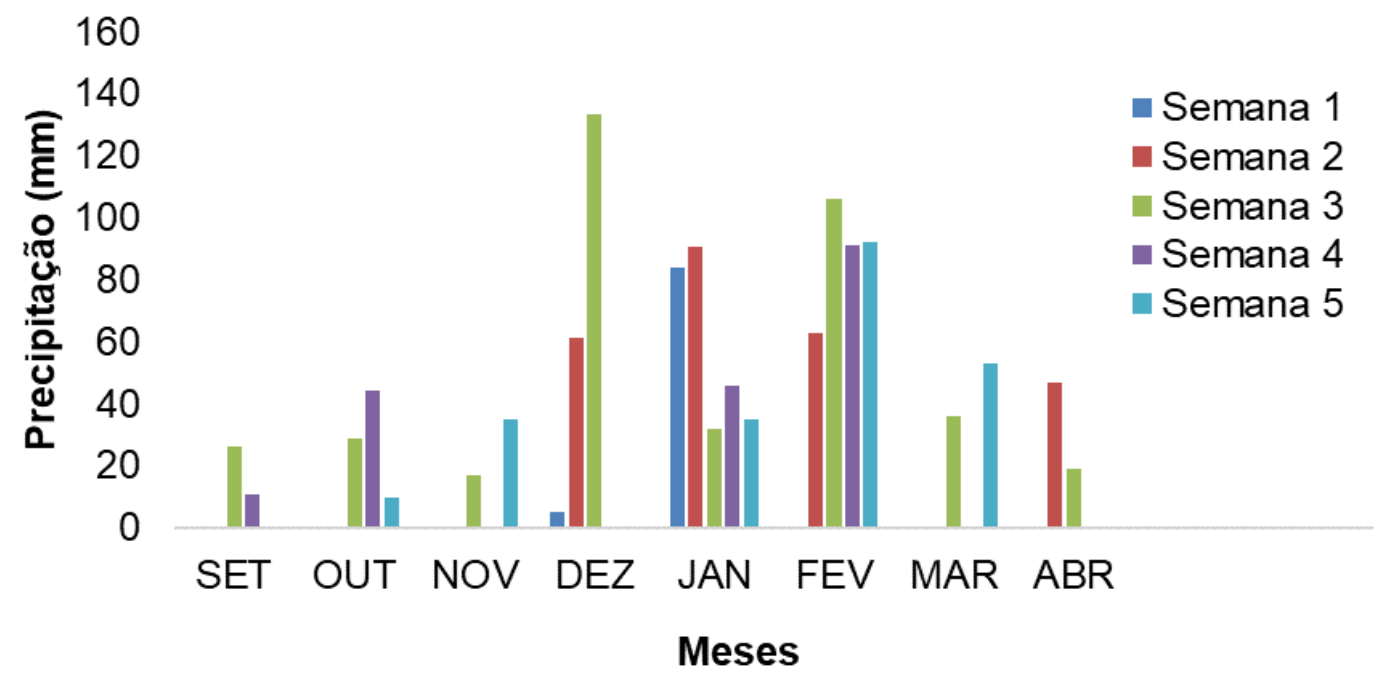

Figura 1. Dados da precipitação semanal no município de Tupã, SP, na safra de 2019/2020. (Fonte: Cooperativa Camap).

A avaliação da ocorrência de virose foi realizada em cada parcela contando-se, em cada uma das 4 linhas úteis dessas parcelas, o número de plantas que apresentavam algum sintoma visual da ocorrência da doença, no dia 13/02/2020, que correspondeu a 111 dias após a semeadura das

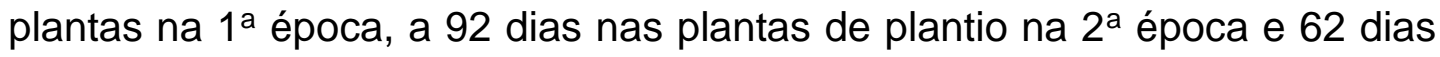
nas plantas de plantio da $3^{a}$ época. 
Nas parcelas do plantio da $1^{\text {a }}$ época não foi verificada sinais da ocorrência da virose. O segundo plantio foi o mais afetado, registrando um número significativo de plantas com sintomas visuais de ataque do vírus. Nas plantas de plantio de $3^{\mathrm{a}}$ época, foi verificada a ocorrência de virose, mas com uma menor frequência.

A colheita foi realizada em 04/03/2020 para o plantio das parcelas de 1. ${ }^{a}$ época (130 dias após a semeadura), 23/3/2020 (130 dias após a semeadura) para as parcelas de $2^{a}$ época e em 17/04/2020 para as parcelas de $3^{\mathrm{a}}$ época (123 dias após a semeadura). Para avaliação da produtividade foram colhidos, das linhas úteis de cada parcela, 8 metros divididos em 4 segmentos de 2 metros. Após a colheita as vagens foram separadas manualmente e secas ao sol até secagem completa das vagens.

\section{Resultados e discussão}

As produtividades médias das linhagens variaram entre $6.154 \mathrm{Kg} \mathrm{ha}^{-}$

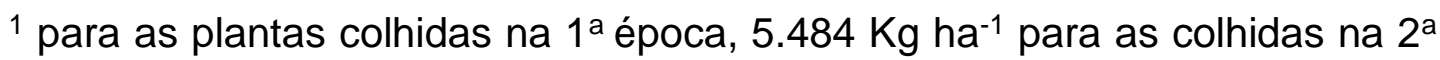
época até $4.253 \mathrm{Kg} \mathrm{ha}^{-1}$ para as colhidas na $3^{\mathrm{a}}$ época de avaliação (Tabela 1). Como era de se esperar, em condições normais de cultivo, as semeaduras nos primeiros meses da estação de cultivo favoreceram a obtenção de maiores produtividades.

A presença de virose nas plantas cultivadas nas $2^{a}$ e $3^{a}$ épocas também pode ter influenciado na ocorrência de menores produtividades em relação à $1^{\mathrm{a}}$ época de cultivo (Tabela 1 ). $\mathrm{Na}$ avaliação das linhagens na $1^{\mathrm{a}}$ época de cultivo, verificou-se que as linhagens da Série 11 foram as mais produtivas, com a linhagem 11.20 expressando alto potencial produtivo (7.556 Kg ha-1).

$\mathrm{Na}$ avaliação das linhagens plantadas na $2^{\mathrm{a}}$ épocas sobressaíram a 10.677 e 10.719 , com $6.194 \mathrm{Kg} \mathrm{ha}^{-1}$ e $6.174 \mathrm{Kg} \mathrm{ha}^{-1}$, respectivamente. $\mathrm{E}$ para as linhagens plantadas na $3^{\text {a }}$ época, verificou-se que as mais produtivas foram a $10.677 \mathrm{com} 5.453 \mathrm{Kg} \mathrm{ha}^{-1}$, a $11.20 \mathrm{com} 4.839 \mathrm{Kg} \mathrm{ha}^{-1}$, e a $599 \mathrm{com} 4.811 \mathrm{Kg} \mathrm{ha}^{-1}$ (Tabela 1 ). 
Tabela 1. Produtividade de linhagens e cultivares de amendoins semeados em três épocas, no município de Tupã - SP, na safra de 2019/2020.

\begin{tabular}{lcccc}
\hline Genótipos & 1 $^{\mathrm{a}}$ Época & 2 $^{\mathrm{a}}$ Época & 3 $^{\mathrm{a}}$ Época & ${\text { Médias }(\text { Tocher })^{1}}$ \\
\hline L.11.20 & 7.556 & 5.237 & 4.839 & $5.877(3)$ \\
L.11.27 & 6.208 & 5.118 & 3.739 & $5.022(1)$ \\
L.11.29 & 6.653 & 5.609 & 3.247 & $5.170(2)$ \\
L.10.677 & 6.201 & 6.194 & 5.453 & $5.959(3)$ \\
L.10.719 & 5.583 & 6.174 & 3.369 & $5.042(1)$ \\
L. 599 & 6.028 & 4.785 & 4.811 & $5.208(2)$ \\
IAC Sempre & 5.444 & 5.187 & 4.324 & $4.985(1)$ \\
IAC OL5 & 5.667 & 5.826 & 4.006 & $5.166(2)$ \\
IAC OL3 & 6.049 & 5.222 & 4.486 & $5.252(2)$ \\
\hline Médias & 6.154 & 5.484 & 4.253 & 5.297
\end{tabular}

A interação genótipos $x$ ambientes foi ns. O F (3 épocas) $=0,3042$ ns. 1 Entre parêntese o agrupamento de médias de Tocher.

Na média das 3 épocas avaliadas, a linhagem 10.677 mostrou a maior produtividade, com $5.959 \mathrm{Kg} \mathrm{ha}^{-1}$, seguida da linhagem $11.20 \mathrm{com}$ $5.877 \mathrm{Kg} \mathrm{ha}^{-1}$. Considerando as 3 épocas de semeadura, a linhagem 10.677 mostrou a maior estabilidade produtiva quando comparada as demais linhagens, tendo apresentado bom desempenho produtivo na $1^{\text {a }}$ época e se destacado também nas demais épocas.

Verificou-se que a virose realmente ocorreu na $2^{\mathrm{a}}$ e $3^{\mathrm{a}}$ épocas de semeadura (Tabela 2), com intensidade um pouco maior na $2^{\mathrm{a}}$ época de semeadura (plantio realizados em novembro). Tanto na $2^{a}$ quanto na $3^{a}$ época de semeadura, pôde-se considerar que a infestação do vírus foi de moderada intensidade devido ao número de plantas encontradas que apresentavam sintomas de virose. Ou seja, verificou-se em torno de 7 plantas com sintoma em 10 metros lineares, na linhagem onde se observou maior infecção pela virose.

Mesmo com moderada infestação geral, notou-se variabilidade entre os genótipos avaliados, tanto na $2^{\mathrm{a}}$ como na $3^{\mathrm{a}}$ época de semeadura. $\mathrm{Na} 2^{\mathrm{a}}$ 
época, houve significância apenas entre a linhagem 11.20, a mais infectada pela virose e a linhagem 10.677, a menos infectada, com 1,75 plantas/10 m de linha.

$\mathrm{Na} 3^{\mathrm{a}}$ época de cultivo, a linhagem 10.677 novamente se destacou, juntamente com a cultivar IAC Sempre Verde, diferindo estatisticamente da linhagem 10.719, a mais afetada. Na média das duas épocas, a linhagem 10.677 foi a que se destacou, apresentando apenas 1,75 plantas infectadas em 10 metros de linha.

Tabela 2. Número de plantas infestadas com vírus (NPV) em genótipos de amendoim, em Tupã - SP, na safra de 2019/2020.

\begin{tabular}{lccc}
\hline Genótipos & 2a época & $3^{\mathrm{a}}$ época & Médias/Épocas \\
\cline { 2 - 4 } & NPV & NPV & NPV \\
\hline L. 11.20 & $7,50 \mathrm{a}$ & $4,25 \mathrm{ab}$ & $5,88 \mathrm{a}$ \\
L. 11.27 & $5,50 \mathrm{ab}$ & $3,75 \mathrm{ab}$ & $4,63 \mathrm{abc}$ \\
L. 11.29 & $6,50 \mathrm{ab}$ & $4,25 \mathrm{ab}$ & $5,38 \mathrm{ab}$ \\
L. 10.677 & $1,75 \mathrm{~b}$ & $1,75 \mathrm{~b}$ & $1,75 \mathrm{c}$ \\
L. 10.719 & $6,25 \mathrm{ab}$ & $4,75 \mathrm{a}$ & $5,50 \mathrm{ab}$ \\
L. 599 & $6,25 \mathrm{ab}$ & $2,75 \mathrm{ab}$ & $4,50 \mathrm{abc}$ \\
IAC Sempre Verde & $3,00 \mathrm{ab}$ & $1,75 \mathrm{~b}$ & $2,38 \mathrm{bc}$ \\
IAC OL5 & $6,00 \mathrm{ab}$ & $4,25 \mathrm{ab}$ & $5,13 \mathrm{ab}$ \\
IAC OL3 & $6,25 \mathrm{ab}$ & $4,25 \mathrm{ab}$ & $5,25 \mathrm{ab}$ \\
\hline
\end{tabular}

Médias seguidas de uma mesma letra nas colunas não diferem entre si a $5 \%$ de probabilidade pelo teste de Tukey.

\section{Conclusões}

As épocas de plantio, acentuadas pela ocorrência de virose, influenciaram a produtividade e mostraram diferenças em desempenho produtivo entre os genótipos. A linhagem 10.677 se destacou pela estabilidade produtiva e menor percentual de infecção pela virose, sugerindo resistência à doença. 


\section{Referências}

CAMELO-GARCÍA, V. M.; LIMA, É. F. B.; MANSILLA-CÓRDOVA, P. J.; REZENDE, J. A. M.; KITAJIMA, E. W.; BARRETO, M. Occurrence of Groundnut ringspot vírus on Brazilian peanut crop. Journal of General Plant Pathology, v.80, n.3, p. 282-286, 2014. http://dx.doi.org/10.1007/s10327-014-0518-2

CULBREATH, A. K.; TODD, J. W.; BROWN, S. L. Epidemiology and management of Tomato spotted wilt in peanut. Annual Review of $\begin{array}{lll}\text { Phytopathology, } & \text { v. } 41, & \text { p.53-75, }\end{array}$ http://doi.org/10.1146/annurev.phyto.41.052002.095522

GODOY, I. J.; MORAES, S. A.; ZANOTTO, M. D.; SANTOS, R. C. Melhoramento do Amendoim. In: A. Borém (editor). (Org.). Melhoramento de Plantas: Culturas Agronômicas. 2. ed., Viçosa, MG, 2005, 817p.

MICHELOTTO, M.D.; CARREGA, W.C.; LAMANA, L.E.P.; DE SOUZA, T.M.; GODOY, I.J.; DOS REIS, L.D.N.A.; SALES, A.L.M.; CARVALHO, R.D.C.P. Losses caused by Groundnut ringspot tospovirus in peanut crop in the State of São Paulo. Semina: Ciências Agrárias, v.40, n.6, supl. 3, p.3429-3442, 2019.

0359.2019v40n6Supl3p3429

SANTOS, J. F. ; GODOY, I.J. ; MORAES, A.R.A.; MICHELOTTO, M. D.; FREITAS, R.S.; BOLONHEZI, D. ; CAVICHIOLI, J.C. ; MARTINS, A.L.M. Productivity, adaptability and stability of high-oleic peanut lines in the State of São Paulo. Bragantia, v. 77, p. 265-272, 2018. http://dx.doi.org/10.1590/1678-4499.2017152 